\title{
Coexistence of Autism and Ring Chromosome 22
}

\author{
Esra Sizer $^{1 *}$, Tuğba Yüksel ${ }^{1}$, Diclehan Oral $^{2}$ \\ ${ }^{1}$ Department of Child and Adolescence Psychiatry, Dicle University School of Medicine, Diyarbakur/Turkey \\ ${ }^{2}$ Department of Medical Genetics, Dicle University School of Medicine, Diyarbakir/Turkey
}

\begin{abstract}
The incidence of ring chromosome 22, which was first described by Weber et al. in 1968, is not known yet. Phenotypic features such as craniofacial anomalies, growth and developmental retardation, hypotonia, mental retardation, delay in motor skills, and syndactyly in the 2 nd and 3rd toes are observed in cases with ring chromosome 22 . Ring chromosome 22 abnormality has rarely been reported in children diagnosed with autism spectrum disorder. Herein, we will disarss a sixyear old boy having a karyotype of 46, XY, r (22) (p11.2q13), ish del (22qter) (MS607-) on cytogenetic examination who was diagnosed with autism spectrum disorder.
\end{abstract}

Key Words: Ring chromosome 22, 22q13, autism

\section{Introduction}

Autism spectrum disorder (ASD) is a neurodevelopmental disorder characterized by limited or repetitive behavioral patterns, as well as limitations in verbal or non-verbal social communication and interaction skills (1). The mean age of diagnosis of autism spectrum disorders is approximately 3 years and the incidence is estimated to be 1 in 68 children. It is reported to be 3-4 times more common in boys than girls (2). The etiological and phenotypic heterogeneity of ASD results in differences in the development and types of symptoms (3). ASD has a multifactorial etiology that has been impaired by the influence of environmental factors and a number of genes that are effective in the development and functioning of neurons. Genetic disorders associated with autism include Rett syndrome, Fragile $\mathrm{X}$ syndrome, tuberous sclerosis, neurofibromatosis type I and type II (NF I and II) (2). By using cytogenetic analysis methods, structural chromosomal changes have been shown in 3\% to $6 \%$ of autism cases (4). The most common chromosomal changes are duplication of $15 \mathrm{q} 11-\mathrm{q} 13$ and deletions of $2 \mathrm{q} 37$, $22 \mathrm{q} 11.2$, 22q13.3 (5). After a deletion in the chromosomes, the ring chromosome structure is formed by the recombination of the remaining sticky ends due to its adhesive property (6).

The phenotype of ring chromosome patients, usually resulting from subtelomeric deletions, overlaps with the syndromes caused by deletion of the ends of the relevant chromosome. The incidence of the ring chromosome 22, which was first described by Weber et al. in 1968, is not known yet (7). The association of autism with the ring $22^{\text {nd }}$ chromosome, of which phenotypic properties are not precisely classified, has rarely been reported (8-18). Herein, we will discuss a case of autism accompanied by a ring chromosome 22 below.

\section{Case Report}

A 6-year-old boy was admitted to our outpatient clinic with complaints of restlessness, crying, elf-harm, and destructive behaviors towards his surroundings and objects. There was no kinship between his mother and father. He was born as youngest child of eight children from a 41-year-old healthy mother and 42year-old healthy father. In his detailed anamnesis, we learned that he could not express his needs, had been restless since birth and was constantly crying, giving harm to objects in surrounding, beat the children, self-biting behavior, eats inedible objects such as the door-edge plastics, avoid eye contact, not obeying the commands, not responding at the call, does not interact with his peers, exhibit turning stereotypic movements such as turning around and flapping hands, feels uncomfortable to be hugged, misused the toys, had an interest in rotating objects, does not react to pain stimuli, unable to dress without help, and had difficulty to fall asleep. In his medical history, we learned that the patient had no complications during the pregnancy period and was born at 2,750 g with cesarean section at term. He had been hypotonic from the neonatal period, he started walking at 3 years of age, and he cannot say any words and could not gain toilet training yet. The family history was unremarkable. The patient cried incessantly 


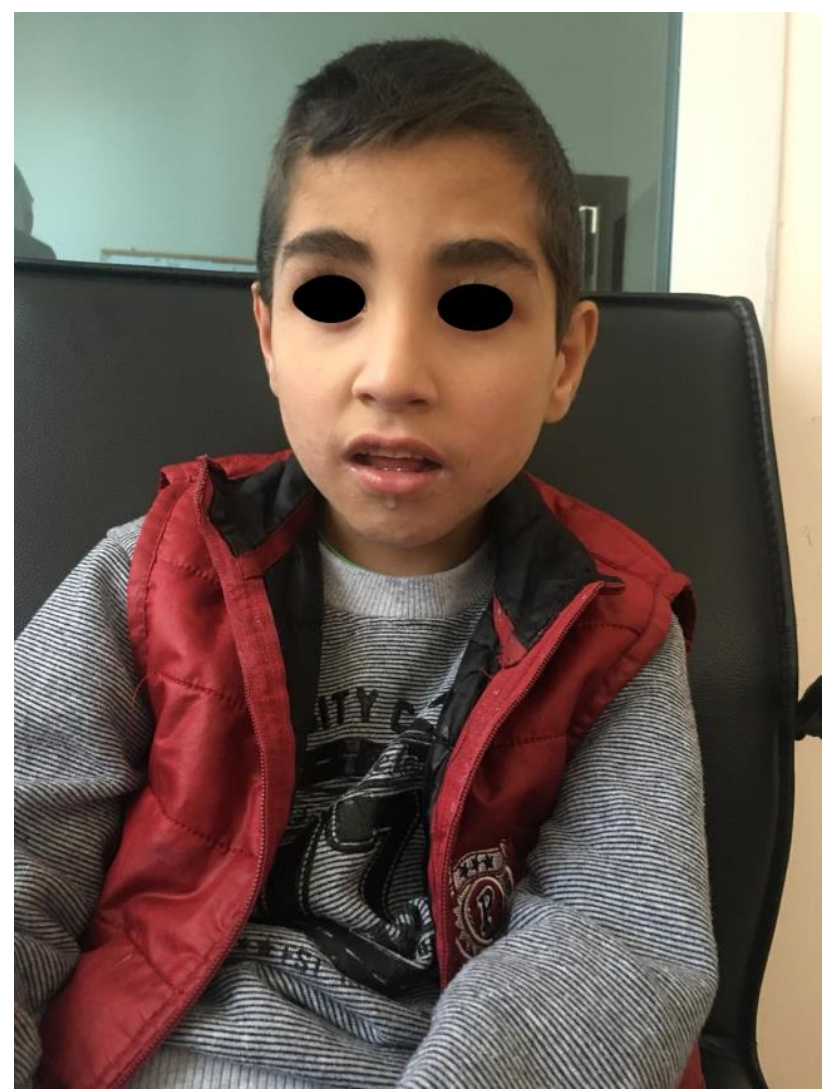

Fig. 1. Frontal view of the patient at 6 years; microcephaly, long eyelashes, full eyebrows, flat nasal bridge and large ears

throughout the psychiatric examination, and we observed that he did not establish eye contact, he had no interest to surrounding and people around and he did not respond calls with his name and did not follow commands. On physical examination, he had a height of $113 \mathrm{~cm}$ (10 $10^{\text {th }}-25^{\text {th }}$ percentile), weight of 15 $\mathrm{kg} \quad\left(<3^{\text {rd }}\right.$ percentile), occipitofrontal head circumference of $47 \mathrm{~cm}\left(<3^{\text {rd }}\right.$ percentile), retardation in motor skills, flat nasal bridge, full eyebrows, long eyelashes, and large ears were noticed (Figure 1). EEG and magnetic resonance imaging (MRI) of the patient were evaluated within normal limits, whose mental capacity was noted as retarded compared to his peers. Evoked auditory brainstem response test showed bilateral mild hearing loss. Anamnesis, mental status examination and psychometric tests revealed autism spectrum disorder and severe cognitive developmental retardation according to DSM V diagnostic criteria. The informed consent from for the participation of our case to the study has been taken from his parents.

Cytogenetic Evaluation FISH analysis and Results: High-resolution Giemsa-banding and Cbanding (550-band) were performed in metaphase chromosomes of the proband obtained from peripheral blood lymphocytes. The karyotype of the patient was found to have 46, XY, r (22) (p11.2q13)

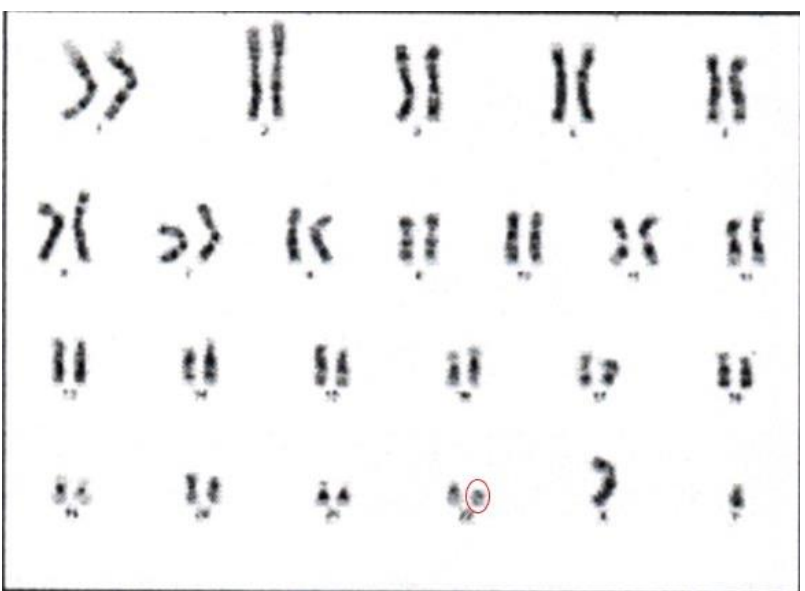

Fig. 2. Karyotype showing 46,XY, r(22) (p11.2q13)

chromosomes in a total of 20 metaphases. Since 22qter deletion is observed in patients with ring chromosome 22, this was confirmed by FISH analysis using 22q telomeric probe which detected a deletion in this region (Figure 2). The cytogenetic evaluation demonstrated the patient's karyotype as 46, XY, r (22) (p11.2q13), ish del (22qter) (MS607-). The karyotype analysis results of the mother, father and siblings were normal.

\section{Discussion}

Our case was six years old boy who was diagnosed with co-existing ring chromosome 22 disorder and autism. The difference in the clinical appearance of the ring chromosome 22 carriers has been attributed to difference in breakpoints and mosaicism (19). The common findings in cases with ring chromosome 22 are growth retardation, delay in speech or lack of speech, microcephaly, hypotonia, mental retardation, retardation in motor skills, high palate, dental malocclusion, long eyelashes, full eyebrows, craniofacial anomalies, epicanthic fold, flat nasal bridge, syndactyly in the second and third toes, big ears, ataxia, and seizures. Most of these findings were present in our patient. We did not note high palate, dental malocclusion, syndactyly in toes, ataxia, or seizures in our patient.

Cases with ring chromosome 22 are at risk for NF-II development $(20,21)$. Neurofibromatosis-II is characterized by vestibular schwannoma, multiple meningioma and neurofibromas (22). Our case distinctively had a mild hearing loss. However, physical examination and cranial MRI views did not indicate any signs or findings for NF-II. On the other hand, ocular, neurological and dermatological examinations are recommended every two years, as well as audiological examinations and cranial MRI for NF-II in patients with ring chromosome 22 (23).

Autism symptoms, mood disorders, hyperactivity, aggressive behaviors and self-destructive behaviors 
have been reported in cases with ring chromosome 22 in the literature $(16-18,24,25)$. In our literature review, the reason for scarcity of data related to comorbid psychiatric diseases in cases with ring chromosome 22 may be due to the fact that the majority of the published cases are in the childhood period and the long-term follow-up results of these cases have not been reported yet.

22q13 deletion syndrome, also known as PhelanMcDermid syndrome, results from deletions ranging from $100 \mathrm{~kb}$ to $9 \mathrm{Mb}$ in the terminal arm of chromosome 22 (26). Cases with 22qter deletion may show similarities to those with ring chromosome 22 in terms of clinical appearance including hypotonia, retardation in psychomotor development, delay in speech or absence of speech, long eyelashes, thick eyebrows, depressed nasal bridge, dental malocclusion, big ear, epicanthus, epileptic seizures, autism or autism-like findings (27-30). However, growth and developmental retardation is not seen in the cases with isolated 22qter deletion, whereas it has been commonly reported in cases with ring chromosome 22 (27,31). A case having 22q13.3 deletion together with ring chromosome 22 was first reported by Koç et al. from our country (31). In accordance with the previous cases in the literature, we determined growth and developmental retardation in our case with respect to height, weight and head circumference measurements. In this context, growth and developmental retardation in our case was considered as a phenotypic feature of ring chromosome 22.

In conclusion, there are many patients present with clinical picture of delayed psychomotor development, delay in speech, cognitive retardation, autism and autism-like findings. We would like to emphasize that it is important to keep in mind that similar clinical manifestations may have different causes, and referral of suspected cases to genetic analysis is critical to detect possible underlying genetic factors.

\section{References}

1. American Psychiatric Association. Diagnostic and statistical manual of mental disorders (5th ed.). Arlington, VA: American Psychiatric Publishing (2013).

2. Sadock B, Ruiz P. Kaplan \& Sadock's synopsis of psychiatry: behavioral sciences. Walters Kluwer 2015.

3. Wing L, Gould J. Severe impairments of social interaction and associated abnormalities in children: Epidemiology and classification. J Autism Dev Disord 1979; 9: 11-29.
4. Vorstman J, Staal W, Van Daalen E, et al. Identification of novel autism candidate regions through analysis of reported cytogenetic abnormalities associated with autism. Mol Psychiatry 2006; 11: 18.

5. Betancur CJ. Etiological heterogeneity in autism spectrum disorders: more than 100 genetic and genomic disorders and still counting. Brain Res 2011; 1380: 42-77.

6. Schinzel A. Catalogue of unbalanced chromosome aberrations in man. Walter de Gruyter; 2001.

7. Weleber RG, Hecht F, Giblett ER. Ring-G chromosome, a new G-deletion syndrome? Am J Dis Child 1968;115: 489-493.

8. Demirhan O, Tunç E. Phenotypic correlations in a patient with ring chromosome 22. Indian J Hum Genet 2010; 16: 97.

9. Hunter AGW, Ray M, Wang HS, Thompson DR. Phenotypic correlations in patients with ring chromosome 22. Clin Genet 1977; 12: 239-249.

10. Assumpcao FB Brief report: a case of chromosome 22 alteration associated with autistic syndrome. J Autism Dev Disord 1998; 28: 253-256.

11. Battini R, Battaglia A, Bertini V, et al. Characterization of the phenotype and definition of the deletion in a new patient with ring chromosome 22. Am J Med Genet 2004; 130: 196-199.

12. Jeffries AR, Curran S, Elmslie F, et al. Molecular and phenotypic characterization of ring chromosome 22. Am J Med Genet 2005; 137: 139-147.

13. Lam A, Lai K, Lam S. Case Report Distinctive Phenotype in a Case of Ring Chromosome 22 with Features of 22q13. 3 Deletion Syndrome. HK J Paediatr 2006; 11: 317-319.

14. Mahajan S, Kaur A, Singh J. Ring chromosome 22: a review of the literature and first report from India. Balk J Med Genet 2012; 15: 55-59.

15. Gibbons B, Tan SY, Tam PY. Ring chromosome 22 resulting in partial monosomy in a mentally retarded boy. Singapore Med J 1999; 40: 273-275.

16. De Mas P, Chassaing N, Chaix Y, et al. Molecular characterisation of a ring chromosome 22 in a patient with severe language delay: a contribution to the refinement of the subtelomeric 22q deletion syndrome. J Med Genet 2002; 39: e17-e. 
17. MacLean JE, Teshima IE, Szatmari P, et al. Ring chromosome 22 and autism: report and review. Am J Med Genet 2000; 90: 382-385.

18. Guilherme RS, Soares KC, Simioni M, et al. Clinical, cytogenetic, and molecular characterization of six patients with ring chromosomes 22, including one with concomitant 22q11. 2 deletion. Am J Med Genet 2014; 164: 1659-1665.

19. Lejeune J. On the duplication of circular structures. Ann Genet 1968; 11: 71-77.

20. Denayer E, Brems H, De Cock P, et al. Pathogenesis of vestibular schwannoma in ring chromosome 22. BMC Med Genet 2009; 10: 97.

21. Zirn B, Arning L, Bartels I, et al. Ring chromosome 22 and neurofibromatosis type II: proof of two-hit model for the loss of the NF2 gene in the development of meningioma. Clin Genet 2012; 81: 82-87.

22. Evans DGR, Huson S, Donnai D, et al. A clinical study of type 2 neurofibromatosis. QJM-Int J Med 1992; 84: 603-618.

23. Lyons-Warren AM, Cheung SW, Holder JL. Clinical Reasoning: A common cause for Phelan-McDermid syndrome and neurofibromatosis type 2 One ring to bind them. Neurology 2017; 89: 205-209.

24. Sovner R, Stone A, Fox C. Ring chromosome 22 and mood disorders. J Intellect Disabil Res 1996; 40: 82-86.
25. Reeve A, Shulman SA, Zimmerman AW, et al. Methylphenidate therapy for aggression in a man with ring 22 chromosome: report and literature review. Arch Neurol 1985; 42: 6972.

26. Phelan MC. Deletion 22q13. 3 syndrome. Orphanet J Rare Dis 2008; 3: 14.

27. Phelan K, Rogers RC, Boccuto L. PhelanMcDermid Syndrome. GeneReviews ${ }^{\circledR}$ [internet]: University of Washington, Seattle; 2018.

28. Durand CM, Betancur C, Boeckers TM, et al. Mutations in the gene encoding the synaptic scaffolding protein SHANK3 are associated with autism spectrum disorders. Nat Genet 2007; 39: 25

29. Philippe A, Boddaert N, Vaivre-Douret L, et al. Neurobehavioral profile and brain imaging study of the 22q13. 3 deletion syndrome in childhood. Pediatrics 2008; 122: 376-382.

30. Cusmano-Ozog K, Manning MA, Hoyme HE. 22q13. 3 deletion syndrome: a recognizable malformation syndrome associated with marked speech and language delay. Am J Med Genet Part C: Seminars in Medical Genetics 2007; 145: 393-398.

31. Koç A, Karaer K, Ergun MA, et al. A case with a ring chromosome 22. Turk J Pediatr 2008; 50: 193. 